\title{
Pengembangan alat uji impak charpy di bagian pengereman, berat pendulum, dan skala ukur pada mesin impak charpy di Laboraturium Teknik Mesin Unhasy
}

\author{
Budy Prasetyo Adi ${ }^{*}$, Mochammad Arif Irfa' ${ }^{\prime}{ }^{2}$, Mohammad Munib Rosadi ${ }^{3}$ \\ Program Studi Teknik Mesin, Fakultas Teknik, Universitas Hasyim Asy'ari ${ }^{1,3}$ \\ JI. Irian Jaya 55 Tebuireng Tromol Pos IX Jombang Jatim Telp. (0321) 861719 (Hunting), \\ 864206, 851396, 874685 Fax. 874684 \\ Corresponding author. adi.sajalah.ap@gmail.com
}

\begin{abstract}
The impact test is a test to determine the strength of the material when receiving a load constantly or suddenly. The previous tool did not suited to the test requirements, so it required the development of the pendulum weight sector, the measuring scale, and the addition of a braking system. Therefore, this research was carried out for the development of previous tools so that the test tools could meet the requirements and the testing of the tools using ST 41 and ST 60 carbon steel specimens. This research is a research and development study using ADDIE (analysis, design, development, implementation, and evaluation) as a reference in conducting research. The development of the tool focuses on the pendulum weight to $10.2 \mathrm{~kg}$, replacing the measuring scale and adding a braking system that uses disc brakes. The results of the expert validation questionnaire got a score of $72.63 \%$, the small respondent data questionnaire got a score of $83 \%$ and the large-scale respondents got a score of $85 \%$. This shows that the tool gets a decent score. The results of the performance test of the tool using ST 41 carbon steel with an average impact price of $1.02302732 \mathrm{~J} / \mathrm{mm}$ and carbon steel ST 60 with an average impact price of $1.2422299 \mathrm{~J} / \mathrm{mm}$. This study shows that there is an average difference in the impact price between ST 41 carbon steel and ST 60 carbon steel as indicated by the Sig. (2-tailed) value of 0.484 using independent sample test T-test data processing.
\end{abstract}

Keywords: Impact Test, Charpy Method, ASTM E23, Steel ST 41 and Steel ST 60.

\begin{abstract}
Abstrak
Pengujian impak merupakan suatu pengujian untuk mengetahui besar kekuatan bahan material disaat menerima beban secara konstan atau tiba-tiba. Alat sebelumnya belum memenuhi syarat pengujian maka diperlukan pengembangan pada sektor berat pendulum, skala ukur dan ditambahkanya sistem pengereman. Maka dari itu dilakukan penelitian ini untuk pengembangan alat sebelumnya agar alat uji bisa memenuhi syarat dan pengujian alat menggunakan spesimen baja karbon ST 41 dan ST 60. Penelitian ini merupakan penelitian pengembangan atau research dan development dengan menggunakan ADDIE (analysis, design, development, implementation dan evaluation) sebagai acuan dalam pengerjaan penelitian. Pengembangan alat menitik beratkan pada pada berat pendulum menjadi $10,2 \mathrm{~kg}$, mengganti skala ukur dan penambahan sistem pengereman yang menggunakan rem cakram. Hasil angket validasi ahli mendapatkan skor $72,63 \%$, angket data responden kecil mendapatkan skor $83 \%$ dan responden skala besar mendapatkan skor $85 \%$. Hal ini menunjukkan bahwa alat mendapatkan nilai layak. Hasil uji kinerjaalat menggunakan baja karbon ST 41 dengan hasil rata-rata harga impak 1,02302732 J/mm dan baja karbon ST 60 dengan hasil rata-rata harga impak $1,2422299 \mathrm{~J} / \mathrm{mm}$. Penelitian ini menunjukan bahwa adanya perbedaan rata-rata dari harga impak antara baja karbon ST 41 dengan baja karbon ST 60 yang ditunjukan dari nilai Sig.(2-tailed) 0,484 menggunakan pengolahan data uji T
\end{abstract}


independent sample test.

Kata kunci: Uji Impak, Metode Charpy, ASTM E23, Baja ST 41 dan Baja ST 60.

\section{Pendahuluan}

Semakin bertambahnya kebutuhan akan material terutama logam dalam dunia perindustrian, besi dan baja merupakan salah satu kebutuhan yang mendasar untuk sebuah kontruksi dengan berbagai macam sifat mekanik yang dibutuhkan oleh suatu material ialah berdeba-beda. Sifat mekanik meliputi kekerasan, keuletan dan ketangguhan [1], maka banyak metode untuk menguji sifat mekanik yang dimiliki oleh material tersebut. Pengujian impak merupakan salah satu metode yang digunakan untuk mengetahui kekuatan, kekerasan dan keuletan suatu material dimana pengujian impak dilakukan dengan cara pembebanan secara tiba-tiba dengan syarat dan ketentuan. Pengujian impak memiliki 2 metode dalam proses pembebanan, yang pertama metode charpy merupakan proses pembebanan spesimen secara horizontal dengan takikan membelakangi arah laju pendulum pada metode charpy memiliki ketentuan untuk ukuran spesimen yaitu 55 x 10 x $10 \mathrm{~mm}$ dan spesimen memiliki takikan dengan sudut $45^{\circ}$ dan yang kedua metode izod merupakan proses pembebanan spesimen secara vertikal dengan takikan menghadap searah laju pendulum pada metode izod memiliki ketentuan ukuran spesimen yaitu $75 \times 10 \times 10 \mathrm{~mm}$ dan spesimen memiliki takikan dengan sudut $45^{\circ}$ [2]. Dengan hasil dari pengujian impak akan mempermudah dalam mengetahui kekuatan, kekerasan dan keuletan bahan material yang ditujukan pada sebuah kontruksi.

Banyak telah meriset penelitian mesin uji impak charpy untuk pengujian material kompositberpenguat serat alam (naturalfibre) dengan kekuatan impact maksimal 130 Joule berdasarkan standart American Society for Testing and Materials (ASTM), yaitu ASTM D 5942-96 dan ASTM D 6110-97 [3]. Dalam pengujian terdapat perbedaan signifikan pada spesimen uji setelah diberikan beban. Hal ini disebabkan oleh perbedaan dimensi ketebalan pendulum hasil rancangan dengan kepala pendulum mesin uji impact charpy yang umum. Pada rancangan mesin uji impact charpy, pendulum memiliki dimensi ketebalan, 48,54 mm,sedangkan pendulum mesin uji impact charpy standar institusi, yakni memiliki ketebalan 18,5 mm [4]. Rancang bangun alat uji impact charpy dilakukan demi menunjang mata kuliah ilmu bahan. Pengujian alat menggunakan spesimen baja dengan dimensi $10 \mathrm{~mm}$ x $10 \mathrm{mmx} 55 \mathrm{~mm}$. Hasil pengukuran minat belajar mahasiswa menunjukan indikator ketertarikan sebesar $73,68 \%$ [5].

Penelitian ini dilakukan untuk menyempurnakan alat uji impak charpy yang terdahulu belum susuai dengan pengujian bahan material. Pada penelitian ini akan menyempurnakan alat uji impak charpy yang terdahulu dengan mengubah berat pendulum, skala ukur dan ditambahkanya sistem pengereman dan hasil penyempurnaan alat uji impak charpy akan diujikan dengan baja karbon ST 41 dan baja karbon ST 60.

\section{Tinjauan Pustaka}

Pengujian impak merupakan pengujian kekuatan bahan material saat menerima beban secara konstan dengan jumlah energy yang diserap oleh bahan material selama terjadi patahan. Energi yang diserap adalah ukuran ketangguhan suatu bahan dari keuletan dan kegetasan bahan itu. Dalam pengujian impak memiliki 2 metode yang menjadi standart yaitu metode charpy dan metode izod. Menurut ASTM E23 spesimen pada pengujuan sebagai berikut. Uji impak metode charpy memiliki spesifikasi bahan uji luas $10 \mathrm{~mm}$ x $10 \mathrm{~mm}$ dengan takikan berbentuk $\mathrm{V}$ yang memiliki kedalaman 2 $\mathrm{mm}$ dengan radius pusat $0.25 \mathrm{~mm}$. 
Pengujian dilakukan dengan cara pembebanan dilakukan secara konstan pada titik tengah spesimen dan spesimen dihadapkan membelakangi laju pendulum [1].

Sedangkan metode izod memiliki spesifikasi bahan uji luas penampang 10 $\mathrm{mm} \times 10 \mathrm{~mm}$ dan panjang $75 \mathrm{~mm}$ dan mempunyai takikan berbentuk $\mathrm{V}$ dengan kedalaman $2 \mathrm{~mm}[2]$

\section{Metode Penelitian}

Penelitian ini menggunakan jenis penelitian pengembangan, menjelaskan secara detail penelitian pengembangan yang memiliki 2 tujuan sebagai pengembangan prototype produk dan sebagai perumusan saran metodelogis guna pendesain dan evaluasi prototype tersebut [6]. Setelah memperoleh sebuah data-data angka, kemudian dianalisis dan diolah menjadi sebuah informasi dari kumpulan data-data yang valid dan ilmiah sebagai hasil dari sebuah penelitian [7]. Proses penelitian ini menggunakan metode eksperimental yang melakukan pengujian terhadap beberapa variasi baja karbon ST 41 dan baja karbon ST 60 untuk mengetahui harga impak yang dilakukan dengan alat yang sudah dikembangkan. Skema alur penelitian dapat dilihat pada Gambar 1.

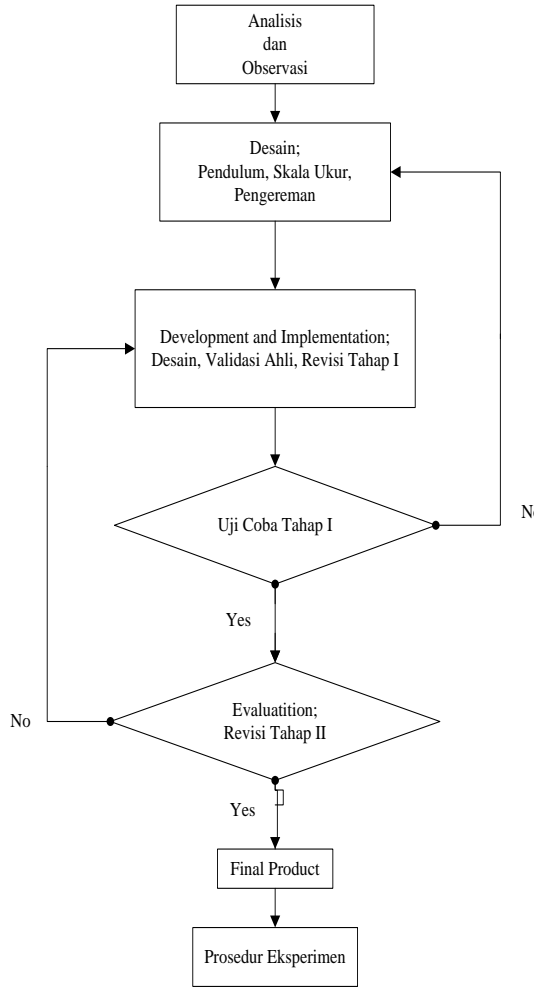

Gambar 1. Flowchart Penelitian

Pada Gambar 1 menjelaskan dengan singkat tahapan peneliti untuk proses pengembangan alat uji impak charpy untuk mendapatkan kelayakan alat dilakukan pengujian validasi ahli dan mahasiswa terhadap alat uji impak charpy. Adapun penunjang dalam pengembangan alat dengan menguji kinerja alat menggunakan sampel baja karbon ST 41 dan baja karbon ST 60 dengan skema eksperimen dapat dilihat pada Gambar 2. 


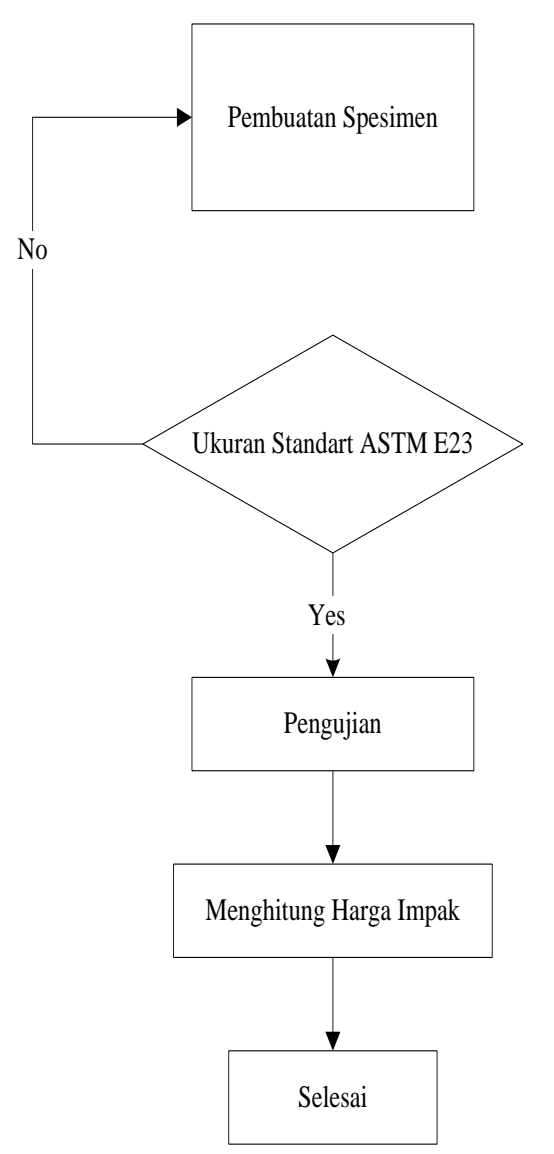

Gambar 2. Flowchart Eksperimen

Pada Gambar 2 menjelaskan dengan singkat runtutan eksperimen untuk mendapatkan harga impak dari bahan uji. Untuk melakukan pengujian dilakukan pembuatan ukuran spesimen maupun bentuk takikan dan setelahnya akan diujikan beberapa kali dimana hasil akan pengujian mendapat harga impak dari bahan uji.

\section{Alat dan bahan}

Penelitian ini menggunakan alat-alat untuk proses pengujian antara lain mesin uji impak charpy yang sudah dikembangkan pada berat pendulum, skala ukur dan penambahan sistem pengereman. Sedangkan bahan menggunakan baja karbon ST 41 dan baja karbon ST 60.

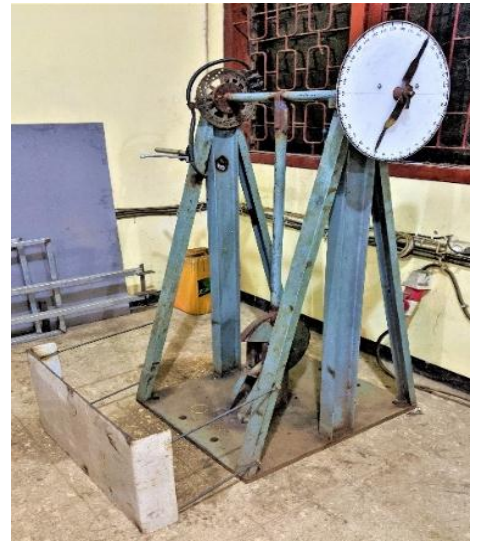

Gambar 3. Alat Uji Impak

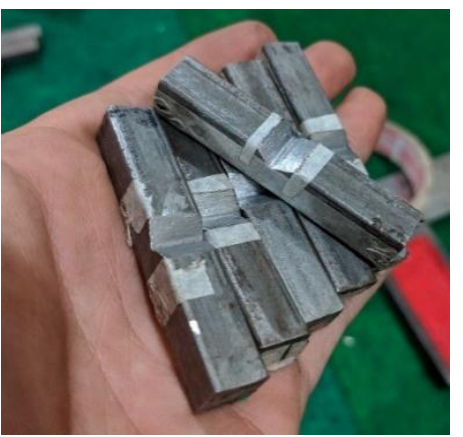

Gambar 4. Baja karbon ST41 dan ST60

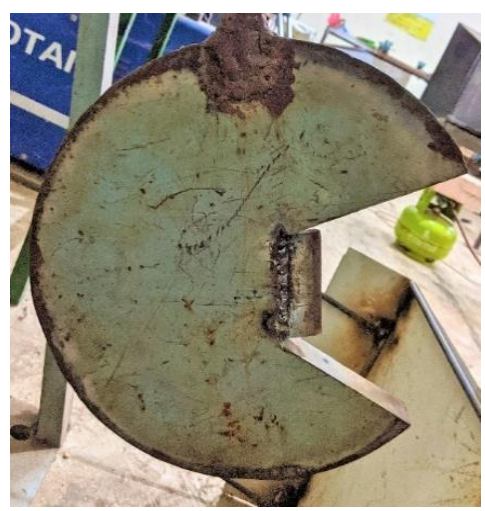

Gambar 5. Pendulum

Pendulum yang digunakan memiliki berat $10,2 \mathrm{~kg}$, bentuk pendulum tidak diubah tetapi mengurangi berat dengan cara mengikis diameter lingkaran pendulum yang berawal $350 \mathrm{~mm}$ menjadi $300 \mathrm{~mm}$. Sebelum pengurangan berat pendulum akan dilepas dari lengan ayun yang bersambungan dengan poros putar pada kerangka alat uji untuk memudahkan pengerjaan. 


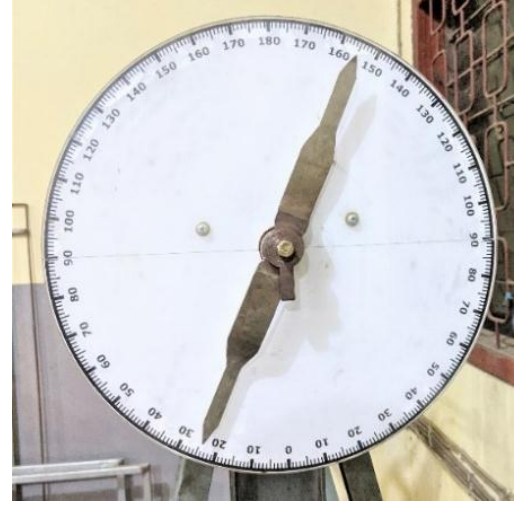

Gambar 6. Skala Ukur

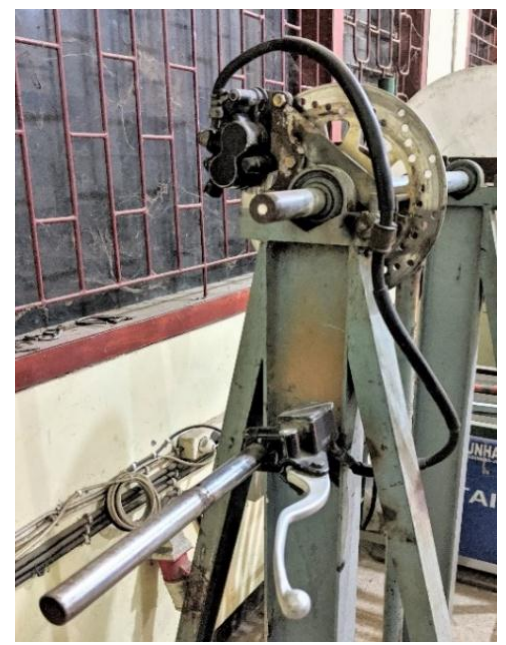

Gambar 7. Sistem Pengereman

\section{Perhitungan harga impak}

Untuk mengetahui nilai harga impak maka harus menggunakan rumus sebagai berikut:

Energi yang diserap pada bahan uji.

$W=m \cdot g \cdot \lambda(\sin \alpha-\sin \beta)$

$A=b / h$

$K=W / A$

\section{Hasil dan Pembahasan}

Hasil dan pembahasan berisi data hasil perhitungan berdasarkan teori dan metode yang digunakan, selain itu juga berisikan hasil kelayakan alat dengan menggunakan angket untuk validasi ahli dan angket mahasiswa dan pengujian baja karbon ST41 dan baja karbon ST60 menggunakan alat yang sudah dikembangkan serta penjelasan.

\section{Berdasarkan uji $\mathrm{T}$ independent sample test. \\ Hasil perhitungan angket kelayakan produk}

Hasil perhitungan berisi data-data yang disajikan dalam bentuk tabel sedemikian rupa, sehingga mempermudah pembaca untuk melakukan referensi rujukan terkait penelitian ini. Isi tabel-tabel berikut tidak lain mencantumkan komponen pendulum, skala ukur dan sistem pengereman yang diberikan nilai interpretasi dengan skala 1 sampai 4 . Dimana angket diberikan kepada validasi ahli untuk memberikan nilai interpretasi terhadap alat uji yang dikembangkan.

Tabel 1. Hasil Penilaian Validasi Ahli

\begin{tabular}{ccc}
\hline komponen & Perolehan & $\%$ \\
\hline Pendulum & 3,866 & $75,01 \%$ \\
\hline $\begin{array}{c}\text { Sistem } \\
\text { pengereman }\end{array}$ & 3,166 & $69,35 \%$ \\
\hline Skala ukur & 3,6 & $73,54 \%$ \\
\hline $\begin{array}{c}\text { Skor yang } \\
\text { diharapkan }\end{array}$ & & $72,63 \%$ \\
\hline
\end{tabular}

Data angket berisikan nilai interpretasi yang diberikan validasi ahli mempunyai komentar dan saran yang akandi perbaiki dengan menjalani revisi tahap I. Tahap selanjutnya angket akan diberikan kepada mahasiswa berskala kecil untuk memberikan nilai interpretasi.

Tabel 2. Hasil Penilaian Skala Kecil

\begin{tabular}{ccc}
\hline Komponen & Perolehan & $\begin{array}{c}\text { Rerata } \\
\text { kategori }\end{array}$ \\
\hline Pendulum & 48 & $80 \%$ \\
\hline Skala ukur & 52 & $87 \%$ \\
\hline $\begin{array}{c}\text { Sistem } \\
\text { pengereman }\end{array}$ & 50 & $83 \%$ \\
\hline
\end{tabular}


Tabel 3. Hasil Penilaian Skala Besar

\begin{tabular}{ccc}
\hline Komponen & Perolehan & $\begin{array}{c}\text { Rerata } \\
\text { kategori }\end{array}$ \\
\hline Pendulum & 249 & $83 \%$ \\
\hline Skala ukur & 256 & $85 \%$ \\
\hline $\begin{array}{c}\text { Sistem } \\
\text { pengereman }\end{array}$ & 262 & $87 \%$ \\
\hline
\end{tabular}

Pada hasil pengujian tahap II merupakan hasil dari tahap sebelumnya yang dimana dengan nilai interpretasi yang diberikan mahasiswa berskala besar "Sangat Baik".

\section{Hasil pengujian spesimen}

Berdasarkan hasil percobaan dengan alat uji impak charpy yang sudah dikembangkan menggunakan bahan uji baja karbon ST41 dan baja karbon ST60 sebagai berikut:

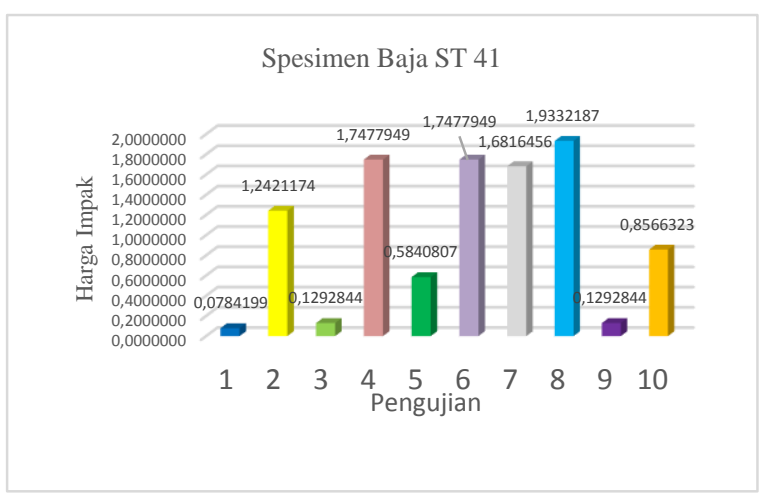

Gambar 8. Pengujian Baja Karbon ST41

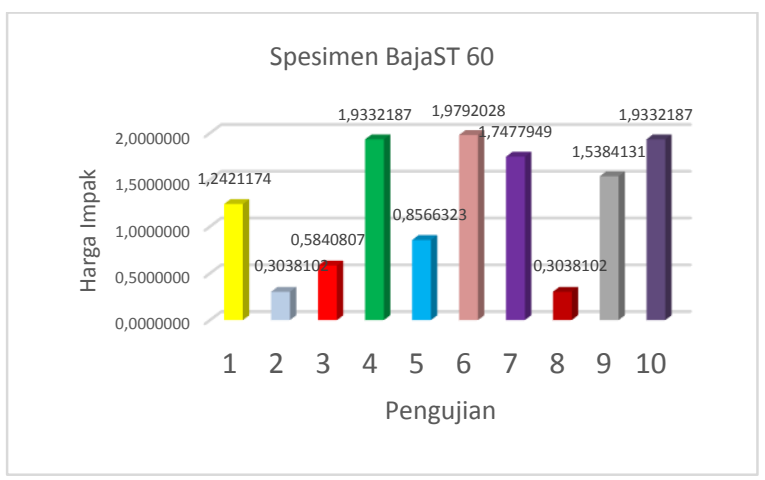

Gambar 9. Pengujian Baja Karbon ST60
Berdasarkan hasil pengujian dengan alat yang sudah dikembangkan dengan menggunakan spesimen baja karbon ST41 dan baja karbon ST60. Pengujian dilakukan sebanyak 10 kali pada setiap spesimen dengan menggunakan ASTM E23 yaitu ukuran spesimen 55 x $10 \quad 10 \mathrm{~mm}$ dan takikan berbentuk $\mathrm{V}$ dengan sudut $45^{\circ}$. Pada pengujian masing-masing spesimen mendapat hasil rata-rata harga impak untuk spesimen baja karbon ST41 1,02302732 $\mathrm{J} / \mathrm{mm}$ dan hasil rata-rata harga impak untuk spesimen baja karbon ST60 1,2422299 $\mathrm{J} / \mathrm{mm}$.

\section{Analisa berdasarkan uji $\mathrm{T}$ independent sample test}

Tabel 4. Hasil Uji T Independent Sample Test

\begin{tabular}{ccc} 
Equal & Sig. & Sig.(2-tailed) \\
\cline { 2 - 3 } Variances & .579 & .484 \\
Assumed & & \\
\end{tabular}

Berdasarkan hasil uji $\mathrm{T}$ independent sample test pada bagian "equal variances assumed" diketahui nilai Sig. (2-tailed) sebesar $0,484>0,05$ dimana dasar pengambilan keputusan dalam uji $\mathrm{T}$ independent sample test dapat di disimpulkan $\mathrm{H} 0$ ditolak dan $\mathrm{H} 1$ diterima. Dengan penjelasan $\mathrm{HO}$ tidak ada perbedaan rata-rata dari harga impak antara spesimen baja karbon ST41 dan baja karbon ST60 jika hasil Sig. (2-tailed) < 0,05 dan penjelasan $\mathrm{H} 1$ adanya perbedaan rata-rata dari harga impak antara spesimen baja karbon ST41 dan baja karbon ST60 jika hasil Sig.(2-tailed) > 0,05.

\section{Kesimpulan}

Berdasarkan dari penelitian, alat uji yang di kembangkan meliputi komponen pendulum mengubah berat menjadi $10,2 \mathrm{~kg}$ dan komponen skala ukur menggantikan dengan bentuk lingkaran yang memiliki jarum penunjuk 2 arah dengan ketinggian yang berbeda dan penambahan komponen sistem pengereman menggunakan rem cakram yang disematkan pada poros purar pendulum. Sedangkan pada pengujian alat 
menggunakan spesimen baja karbon ST41 dan baja karbon ST60 dimana ukuran dari spesimen menggunakan ASTM E23. Dalam pengujian baja karbon ST41 dan baja karbon ST60 menghasilkan harga impak dengan rata-rata $1,02302732 \mathrm{~J} / \mathrm{mm}$ pada pengujian baja karbon ST41 dan $1,2422299 \mathrm{~J} / \mathrm{mm}$ pada pengujian baja karbon ST60. Pada hasil uji T independent sample testadanya perbedaan rata-rata dari harga impak antara spesimen baja karbon ST41 dan baja karbon ST60, dengan ditunjukan nilai Sig. (2-tailed) 0,484.

\section{Referensi}

[1] H. Yopi, "perancangan alat uji impak metode charpy kapasitas 100 joule," jurnal ilmiah teknik mesin, pp. 45-52, 2013.

[2] A. A. U. I. M. I. p. B. P. Jambi, "porawati hilda," jurnal inovator, pp. 15, 2018.

[3] P. Hery And K. I. Made, "Rancang Bangun Mesin Uji Impact Metode Charpy Untuk Pengujian," Publikasi Online Mahasiswa Teknik Mesin, pp. 1-10, 2020.

[4] P. Hery and K. I. Made, "Rancang Bangun Uji Impact Metode Charpy Untuk Pengujian Material Komposit Polimer Serat Alam," Publikasi Online Mahasiswa Teknik Mesin, pp. 1-10, 2020 .

[5] R. M. Munib, Basuki, S. Agung And R. A. Hasbi, "Rancang Bangung Mesin Impak dan Kesan Pertamanya Terhadap Minat Belajar Mahasiswa Pada Matakuliah Ilmu Bahan," Reaktom, pp. 1-6, 2019.

[6] Hanafi, "Konsep Penelitian R\&D Dalam Bidang Pendidikan," Saintifika Islamica, pp. 131-134, 2017.
[7] N. Martono, Metode Penelitian Kuantitatif: Analisis Isi dan Analisis Data Sekunder (Edisi Revisi 2), Jakarta: Rajawali Pers, 2016. 